특집논문-09-14-4-06

$$
\begin{gathered}
\text { 변형된 힐버트 변환을 이용한 디지털 } \mathrm{TV} \text { 방송 채널 및 데이터 분석 } \\
\text { 시스템 }
\end{gathered}
$$

서 영 우 $\left.^{a b}\right)^{\ddagger}$, 이 재 권 ${ }^{a)}$, 목 하 균 ${ }^{a)}$, 최 진 용 ${ }^{b)}$, 서 종 수 ${ }^{b}$

\title{
Channel and Data Analysis System for Digital TV Broadcasting Using Modified Hilbert Transform
}

\author{
Young-Woo Suh ${ }^{\text {ab) })^{\ddagger}}$, Jaekwon Lee ${ }^{\text {a) }}$, Ha-Kyun Mok ${ }^{\text {a) }}$, Jin-Yong Choi ${ }^{\text {b) }}$, and pJong-Soo Seo ${ }^{\text {b) }}$
}

\author{
요 약
}

$\mathrm{ATSC}$ 방식의 디지털 TV 방송의 수신환경을 분석하기 위해 다양한 채널 환경 분석 시스템이 사용되고 있다. 그러나 기존 장비 들은 상용 수신기보다 성능이 떨어져 다중 경로 간섭에 의한 수신기의 수신 불량 현상을 측정하고 분석하기에 어려움이 있다. 이 러한 문제점을 해결하기 위해서 상용 DTV 수신 칩세트를 채널 환경 분석 시스템에 직접 이용하는 것을 고려할 수 있다. 일반적 으로 상용 DTV 칩세트들은 심볼 주파수로 샘플링된 기저대역의 I (In-phase) 채널 데이터 및 동기 신호들을 제공하므로 측정된 I 채널 데이터를 이용하여 좀 더 정확한 신호 품질 및 채널 신호의 분석을 위해서는 효과적인 Q (Quadrature) 채널 데이터의 추출 이 필요하다. 본 논문에서는 DTV 방송 수신환경을 보다 정확하고 효율적으로 분석하기 위하여 DTV 수신 신호 및 채널 분석시스 템의 기술적인 요구 사항을 제시하고, 이러한 요구 사항을 만족하게하고 좀 더 정확한 채널환경 분석을 위해 측정된 기저대역의 I 채널 데이터로부터 힐버트(Hilbert) 변환과정을 개선한 $\mathrm{Q}$ 채널 데이터 추출 방법을 제안한다. 제안된 데이터 및 채널 분석 시스템 은 컴퓨터 모의실험과 실험실 테스트 결과를 통해서 성능을 입증하였으며, 방송신호 측정차량에 장착하여 DTV 동일채널중계기 (DOCR) 필드테스트에서 다중경로간섭 신호의 분석에 적용하였다.

\section{Abstract}

To analyze reception environments of ATSC Digital TV, CIR (Channel Impulse Response) analysis systems are widely applied. The receiving performances of conventional CIR analysis systems are not as good as those of commercial state-of-the-art receivers. There are difficulties in measuring and analyzing reception problems caused by multi-path interferences. To solve these problems, commercial DTV chip sets embedded CIR analysis system is proposed. Generally, commercial chip sets provide baseband I (In-phase) channel data and field or segment sync data. For more precise analysis of measured I channel data, it is necessary to extract Q (quadrature) channel data components as well. This paper presents the technical requirements of CIR analysis system for DTV. In order to satisfy such requirements and measure more accurate magnitude and phase of CIR, a method to derive the quadrature data from the measured in-phase channel data is proposed. The proposed channel analysis system is implemented with a commercial DTV chip set and expedites the data analysis for use on DTV field test vehicles. Computer simulation and laboratory test results are provided to demonstrate the performance of the proposed channel analysis system.

Keyword : ATSC, DTV, CIR, Measurement 


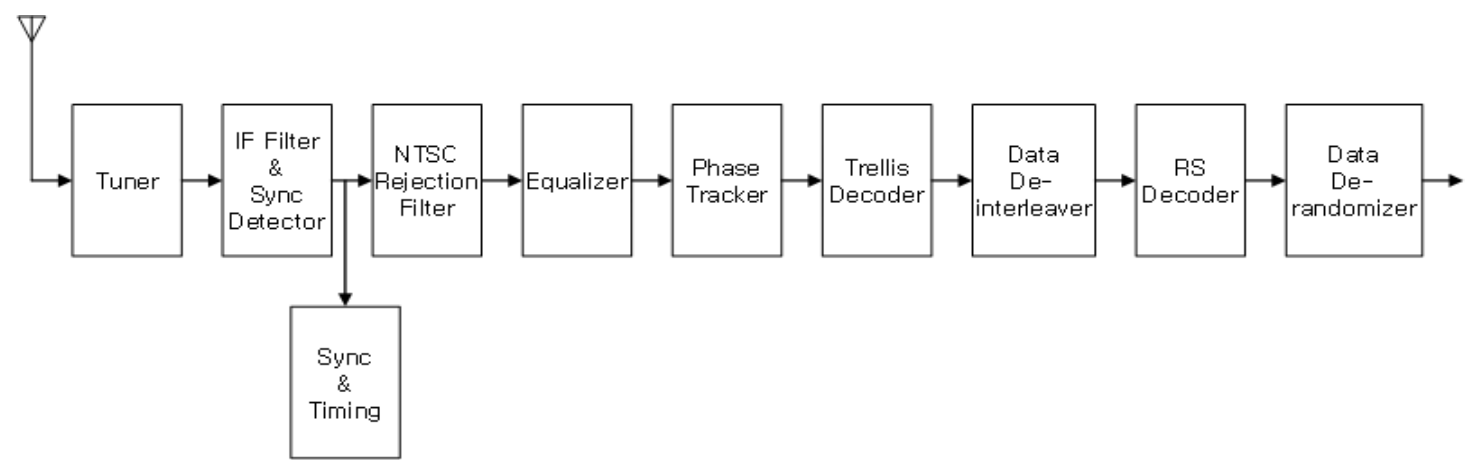

그림 1. ATSC 수신기의 일반적인 구조

Fig. 1. General structure of ATSC receiver

\section{I. 서 론}

ATSC(Advanced Television Systems Committee) DTV 수신기는 그림 1 과 같이 수신신호로부터 파일럿(pilot)을 추출하여 주파수와 타이밍 동기를 획득하는 구조로 이루어 져 있다 ${ }^{[1][2]}$. ATSC DTV는 단일 반송파 전송방식의 특성상 다중경로 간섭 수신 환경에서 수신 동기를 획득하고 정확 한 비디오 신호를 출력하기 쉽지 않으며 수신기마다 수신 성능에서 편차가 있다. 특히, 실내수신 환경에서는 벽면 및 사람에 의해 반사되는 고스트에 의해 수신 성능이 저하되 기도 한다 ${ }^{[3][4]}$.

따라서 DTV 수신 환경 분석을 위해서는 서비스 지역 내의 신호 대 잡음비(SNR; Signal to Noise Ratio) 뿐 아니 라 다중경로 간섭 신호에 대한 채널 응답 특성(CIR; Channel Impulse Response)에 대해서도 고려해야 한다. 특 히, 동일 주파수망(SFN, Single Frequency Network)을 고 려하는 DOCR(Digital On Channel Repeater) 또는 분산중 계기(Distributed Transmission Translator)에서는 이러한 다 중경로 간섭이 심하게 유발될 수 있으므로 이에 대한 철저 한 분석이 요구된다 ${ }^{[5-9]}$. 기존 측정시스템의 채널 분석 장비 로는 R\&S사의 EFA가 대표적이며 현재 방송사 및 국책연

a) 한국방송공사 방송기술연구소

Broadcast Technical Research Institute, KBS

b) 연세대학교

Yonsei University

\# 교신저자 : 서영우(ysuh@kbs.co.kr)

- 접수일(2009년3월18일),수정일(2009년6월15일),게재확정일(2009년6월15일)
구기관 등의 측정차량에서 활용되고 있다 ${ }^{[10]}$. 그러나 $\mathrm{EFA}$ 와 같은 전용 계측기의 경우, 필요한 데이터의 복조를 위한 수신 동기 성능이 최신 사양의 상용 DTV 수신기보다 미흡 하여, DTV 수신이 불량한 곳에서는 채널 환경 측정이 어려 운 단점이 있다.

이러한 문제점을 해결하기 위해서는 CIR 측정시스템의 입력단 성능은 최소한 상용 수신기 수준으로 설계되어야 한다. 그림 2는 2001년 3세대 수신기, 2005년 5세대 수신 기, 2006년 6세대 수신기 등 세대별 상용 DTV 수신기의 다중 경로 간섭신호 제거특성을 보여주는 등화기 성능측 정결과이다 ${ }^{[7]}$. 수신기 칩세트의 '세대(generation)'는 VSB (Vestigial Side Band) 수신기를 처음 개발한 미국 Zenith사 에서 칩세트를 새로 출시할 때마다 갱신되는 것으로 1 세대 칩세트는 1997년도 출시되었으며, 1세대 칩세트가 적용된 수신기를 1 세대 수신기라고 통상 부른다. 그림 2의 측정 방 법은 한 개의 고스트(ghost)를 발생시키고 각 지연 시간별 로 고스트 크기를 변화시킨 후 수신기가 이를 등화하여 처 리할 수 있는 최대 고스트의 크기를 측정하여 그 값을 기록 한 것이다. $0 \mathrm{~dB}$ 고스트는 주 신호의 크기와 같은 크기의 고스트, $-3 \mathrm{~dB}$ 는 주 신호의 크기보다 $1 / 2$ 크기의 고스트를 의미한다. 또한 다중 경로 간섭신호에 대해서 DTV 수신기 는 시간 지연 위치에 따라 선행 및 후행 고스트로 인식하며 그림에서는 약 $\pm 50 \mu \mathrm{sec}$ 의 시간 지연 에 대한 고스트의 등 화 성능을 보여준다. 이 결과로부터 3 세대 수신기보다 5 세 대, 6 세대 수신기의 등화 성능이 우수함을 알 수 있다. 기존 의 계측기가 채택한 VSB 수신 모듈의 성능은 $\mathrm{ATSC}$ 에서 


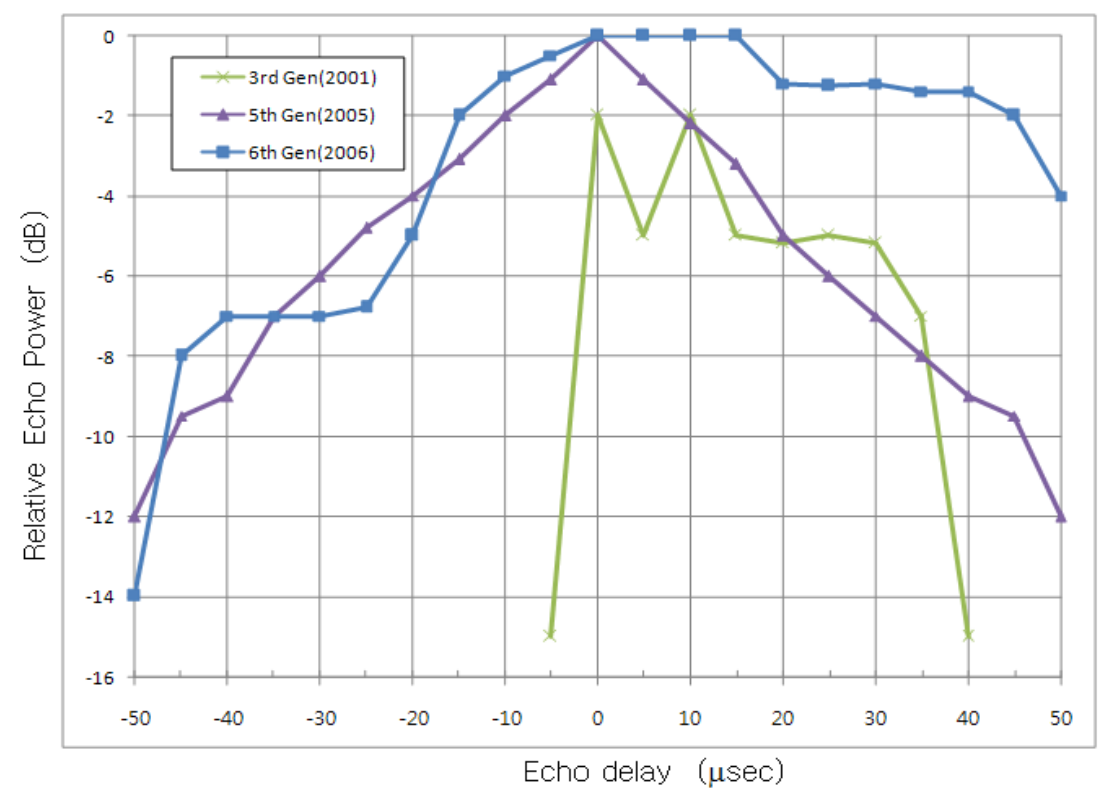

그림 2. ATSC DTV 수신기의 등화기 성능

Fig. 2. Equalization performance of DTV receivers

표준으로 제시하고 있는 3 세대 수신기 수준에 불과하다 ${ }^{[4]}$. 그래서 도심 지역이나 동일 주파수 망 환경에서 다중경로 간섭에 대한 수신 성능 문제로 CIR 및 신호품질이 측정되 지 않는 경우가 있다. 따라서 이에 대한 대안으로 5세대 이 상의 상용 수신 칩세트를 CIR 분석 장비에 활용하는 방안 에 대한 연구가 필요하다.

본 논문에서는 상용 DTV 수신 칩세트가 출력하는 정보 를 최대한 활용하여 DTV 신호 데이터 및 채널 정보를 효율 적으로 분석하는 방법을 제안한다. 이를 위해 기저대역의 I 채널 데이터 신호로부터 위상 정보를 추출하기 위하여 Q 채널 데이터를 복원하는 방법으로 변형된 힐버트(Hilbert) 변환 기법을 적용하였다. CIR에 대해서도 이러한 복소 신 호 복원 기법을 적용하여 보다 정확한 다중경로 신호를 추 출하고 분석하였다 ${ }^{[11]}$. 또한 모의실험을 통하여 신호품질 측정결과와 채널 데이터의 정확성을 입증하였으며, 데이터 및 채널 분석 시스템을 하드웨어로 구현하여 DOCR, 분산 중계기 등 동일 주파수망에서 DTV 채널 환경 분석에 적용 하였다.

\section{DTV 방송 채널 분석 시스템 요구 사항}

\section{VSB 신호의 구성}

ATSC DTV의 디지털 샘플 데이터는 제곱근 상승 코사 인(SRRC, Square Root Raised Cosine) 필터의 펄스 정형 (pulse shaping)이 송수신 단에 적용되며, VSB 필터의 롤오 프(Roll off)는 0.1152 로서 그림 3 과 같이 $5.38 \mathrm{MHz}$ 대역폭 의 정보를 $6 \mathrm{MHz}$ 채널에서 송출할 수 있다. ATSC DTV에 적용 가능한 VSB 변조 방법은 Weaver 방식, Norgaard 방 식, 힐버트 변환방식 ${ }^{[12]}$ 등이 있다.

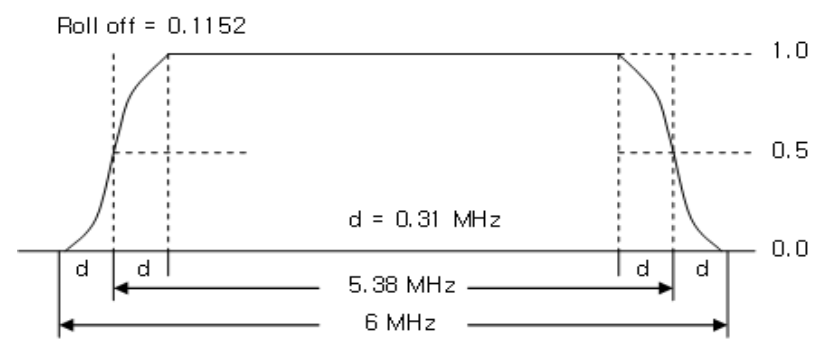

그림 3. ATSC의 VSB RC 필터

Fig. 3. General structure of ATSC VSB RC filter 


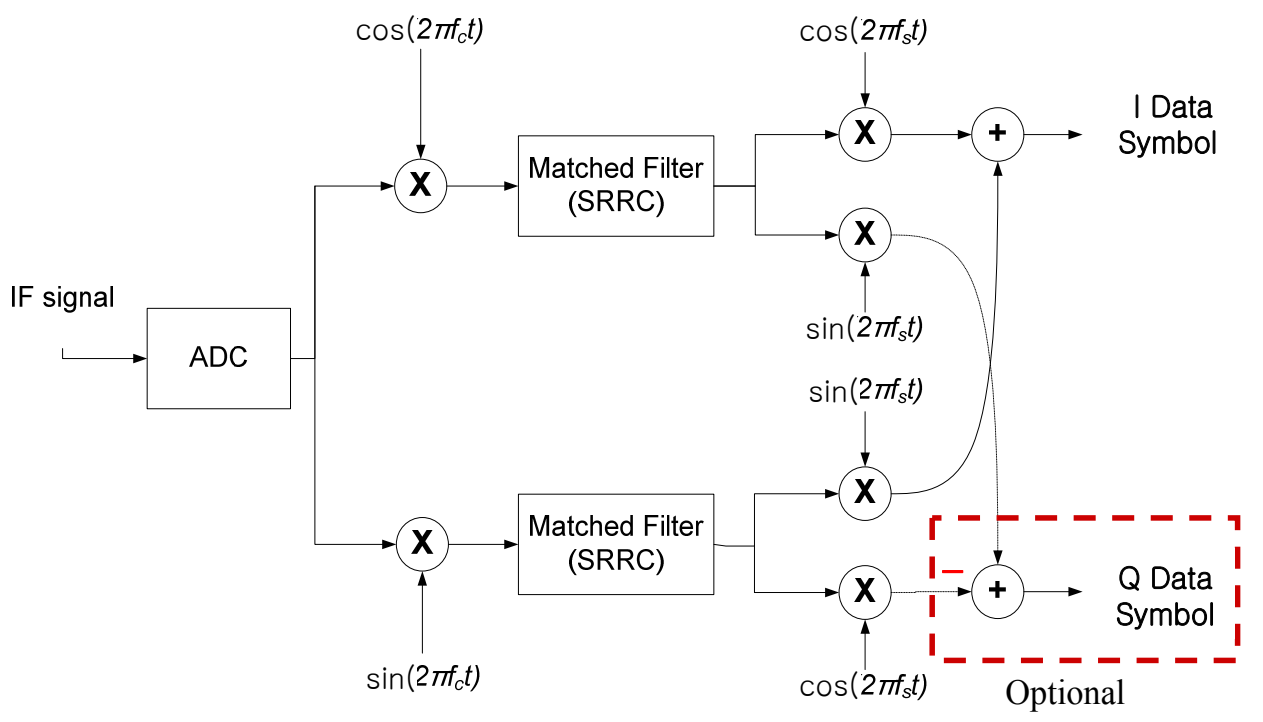

그림 4. VSB 복조부 구성

Fig. 4. Structure of ATSC VSB demodulator

$\mathrm{ATSC}$ 표준에서 제시된 VSB 필터의 응답특성은 다음과 같다.

$\left|H_{R R C}(\omega)\right|= \begin{cases}1, & \text { for } \omega<w_{1} \\ \cos ^{2}\left(\frac{T_{s}}{4 \alpha}\left(\omega+\frac{(1-\alpha) \pi}{T_{s}}\right),\right. & \text { for } w_{1}<\omega<w_{2} \\ 0 & \text { for } \omega>w_{2}\end{cases}$

여기서 $\omega_{1}=(1-\alpha) \pi / T_{s}, \omega_{2}=(1+\alpha) \pi / T_{s}, T_{s}$ 는 심볼 구간을 의미한다.
일반적인 VSB 복조단에서는 그림 4와 같은 형태로 $\mathrm{I} / \mathrm{Q}$ 직교복조에 의해 신호를 수신한다.

그림 4에서와 같이 수신된 I와 $\mathrm{Q}$ 채널 데이터는 주파수 하향과정을 거쳐 그림 5 와 같은 기저대역 신호를 생성한다.

일반 계측기는 대부분 기저대역의 $\mathrm{I} / \mathrm{Q}$ 채널 데이터 정보 를 모두 생성하여 위상 특성 측정 등에 이용하지만 상용 수신기는 I 채널 데이터에 비디오 신호 분석을 위한 모든 정보가 들어 있으므로 $\mathrm{Q}$ 채널 데이터는 내부적으로 위상 보정을 위한 용도로만 사용되며 따로 출력되지 않는 경우
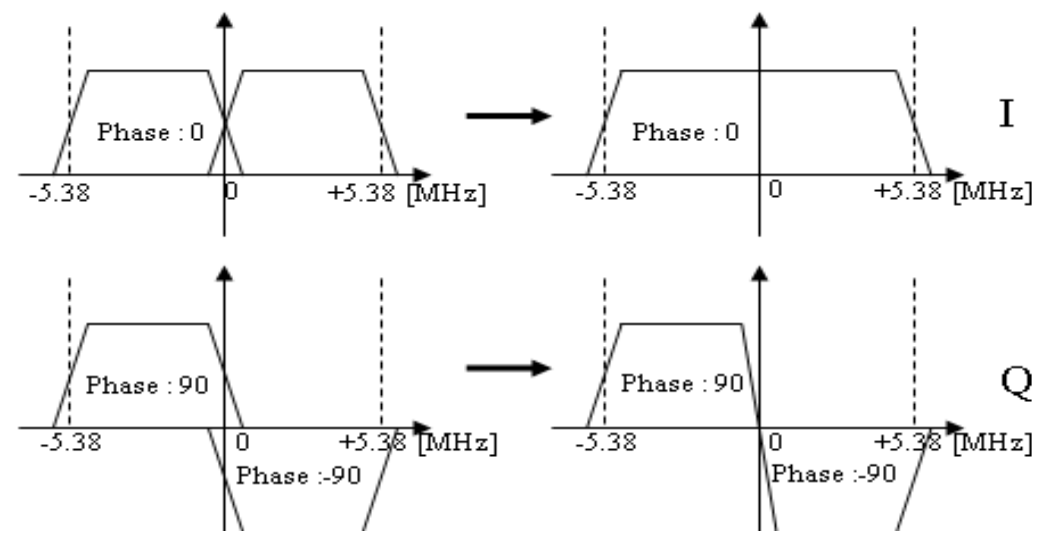

그림 5. VSB I\&Q 채널 데이터 복소 신호처리

Fig. 5. Complex signal processing of VSB I/Q channel data 
가 대부분이다.

\section{DTV 방송 채널 분석 시스템의 요구 사항}

채널(CIR) 분석을 수행하기 위해서는 수신된 I 채널 데이 터를 $\mathrm{ATSC}$ 의 필드 동기신호의 PN511 시퀀스를 이용하여 상호상관(correlation)에 의해서 연산하는 것이 일반적인 방 법이다. 이러한 방식의 시스템은 다중경로 간섭이 심한 환 경에서는 수신 모듈의 성능이 미흡할 경우 CIR 분석 시스 템 자체가 정확히 동작하지 못하는 문제점이 있다 ${ }^{[10]}$. 이러 한 문제점을 해결하려면 다음 요구 사항을 만족하는 CIR 분석 시스템이 필요하다.

1) 상용 DTV 수신 칩세트의 성능을 능가하는 CIR 분석 능력

2) $\mathrm{CIR}$ 과 그에 연동한 데이터의 성상도, $\mathrm{SNR}$ 등 현재 수신기의 수신 상태 모니터링

3) $\mathrm{CIR}$ 과 그에 연동한 비디오/오디오 수신 성능 분석

1)의 조건이 충족되려면 $\mathrm{CIR}$ 측정시스템의 입력단을 상 용 수신기 수준으로 설계해야 하나 기존의 계측기와 같은 다용도 모듈에서는 쉽지 않다. 따라서 이에 대한 대안으로 상용 수신 칩세트를 활용하여 CIR 분석 장비로 활용하는 방안이 요구된다. 상용 칩세트들에서 측정용으로 사용 가 능한 데이터로는 기저 대역의 I (In-phase) 채널 데이터 신 호가 유일하다. 따라서 측정된 I 채널 데이터를 이용하여 $\mathrm{Q}$ 채널 데이터 정보를 추출하고, 이것을 이용하여 SNR과 같은 신호 품질 측정 및 $\mathrm{CIR}$ 측정을 수행할 수 있는 장비를 설계한다면 위의 요구 사항들을 만족하게 할 수 있다.

\section{III. 제안 시스템}

\section{1. 기존 힐버트 변환}

$\mathrm{I}$ 채널 데이터만 측정할 수 있다면 이 정보로부터 $\mathrm{Q}$ 채널 데이터를 구하는 가장 일반적인 방식은 힐버트 변환을 적
용하는 것이다. 다음 수식은 일반적인 힐버트 변환 식을 나 타낸다 ${ }^{[13]}$.

$$
\sigma_{H}(\omega)= \begin{cases}i, & \text { for } \omega<0 \\ 0, & \text { for } \omega=0 \\ -i & \text { for } \omega>0\end{cases}
$$

이러한 방식의 힐버트 변환을 쓰게 되면 쉽게 $\mathrm{Q}$ 채널 데 이터를 얻을 수 있으나 그림 5 에서와 같이 원래 $\mathrm{Q}$ 채널 데 이터와 비교하면 $\mathrm{DC}$ 부근에서 오차가 발생하게 된다. 이것 은 복조과정과 변조과정 모두에서 나타나는 현상이며, 이 러한 힐버트 변조과정을 수식으로 모델링 하여 위의 현상 을 설명하면 다음과 같다 ${ }^{[14]}$. 심볼 스트림 $\mathrm{S}(\mathrm{t})$ 는 다음과 같 이 표현할 수 있다.

$$
s(t)=\sum_{k=0}^{\infty} a_{k} \delta(t-k T),
$$

여기서 $\left\{a_{k}\right\}$ 는 심볼 데이터 열이다.

$\mathrm{DC}$ 를 기준으로 한쪽 대역폭이 $2.69 \mathrm{MHz}$ 인 일반적인 $\mathrm{VSB}$ 필터를 $\operatorname{VSB}(t)$ 라고 정의하고 이 필터의 중심주파수 를 $2.69 \mathrm{MHz}$ 로 $\mathrm{I} / \mathrm{Q}$ 변조하면 다음과 같다. 이는 샘플링 주 파수가 $21.52 \mathrm{MHz}$ 일 때 필터응답을 약 $\pi / 4$ 만큼 변조한 것 과 같다.

$$
\begin{aligned}
& V S B_{I}(t)=V S B(t) \cos (\pi t / 4) \\
& V S B_{Q}(t)=V S B(t) \sin (\pi t / 4)
\end{aligned}
$$

변조된 VSB 필터를 이용하여 입력데이터 $\mathrm{s}(\mathrm{t})$ 에 대해 $\mathrm{VSB}$ 펄스 정형을 수행하면 그림 5 의 $\mathrm{I}$ 와 $\mathrm{Q}$ 채널 데이터는 다음과 같이 표현된다.

$I$ data $(t)=s(t) * \operatorname{VSB}_{I}(t)=s(t) * \operatorname{VSB}(t) \cos (\pi t / 4)$
$Q$ data $(t)=s(t) * \operatorname{VSB}_{Q}(t)=s(t) * \operatorname{VSB}(t) \sin (\pi t / 4)$

여기서 상기 $\mathrm{Q}$ 채널 필터를 이용하지 않고 I 채널 신호를 이용해서 일반적인 힐버트 변환을 통해 $\mathrm{Q}$ 채널 신호를 얻 는다면 $\mathrm{DC}$ 부분의 특성이 그림 6과 같은 형태로 변형되며 그만큼 위상 오차를 일으킨다. 


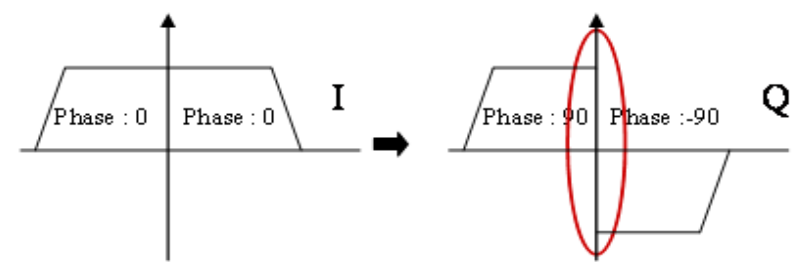

그림 6. 힐버트 변환을 이용한 I 데이터로부터의 $Q$ 데이터 변환

Fig. 6. $Q$ data transform from I data by applying Hilbert Transform

\section{2. 제안하는 변형 힐버트 변환}

기존 힐버트 변환을 VSB Q 채널 데이터 복원에 적용할 때 발생하는 단점을 극복하기 위해서 $\mathrm{DC}$ 부근의 응답특성 을 개선하는 2 가지 방법을 제안하였다.

1) 제안 1 : 선형 힐버트 변환 (Linear Hilbert Transform) 선형 힐버트 변환은 그림 5 에서와 같이 겹쳐지는 부분에 대한 응답특성을 다음 식과 같이 선형적으로 계산하여 산 출한다.

$\sigma_{\text {LinH }}(\omega)= \begin{cases}i, & \text { for } \omega<w_{1} \\ \left(1-2\left(\omega-\omega_{1}\right) /\left(\omega_{2}-\omega_{1}\right)\right) i & \text { for } w_{1}<\omega<w_{2},(6) \\ -i & \text { for } \omega>w_{2}\end{cases}$
여기서 $\mathrm{a}$ 는 롤오프 팩터, $\omega_{1}=-\alpha \pi / T_{s}, \omega_{2}=+\alpha \pi / T_{s}$, $T_{s}$ 는 심볼구간을 의미한다. 이 방식은 비교적 간단한 계산 으로 $\mathrm{Q}$ 채널 데이터 변환 시 $\mathrm{DC}$ 주위의 위상 오차를 많이 개선할 수 있다.

\section{2) 제안 2 : RC 힐버트 변환 (Raised Cosine Hilbert Transform)}

$\mathrm{RC}$ 힐버트 변환은 겹쳐지는 부분에 대한 응답특성을 다 음과 같이 $\mathrm{RC}$ 필터의 수식을 계산하여 다음 식과 같이 산 출한 것이다.

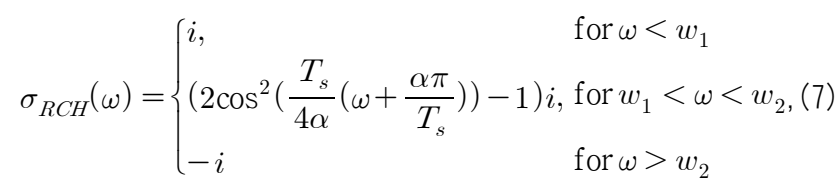

여기서 $\mathrm{a}$ 는 롤오프 팩터, $\omega_{1}=-\alpha \pi / T_{s}, \omega_{2}=+\alpha \pi / T_{s}$, $T_{s}$ 는 심볼구간을 의미한다.

그림 7은 기존의 힐버트 변환과 제안된 2가지의 변형 힐 버트 변환들에 대한 DC 부근의 주파수 응답 특성을 보여주 고 있다.

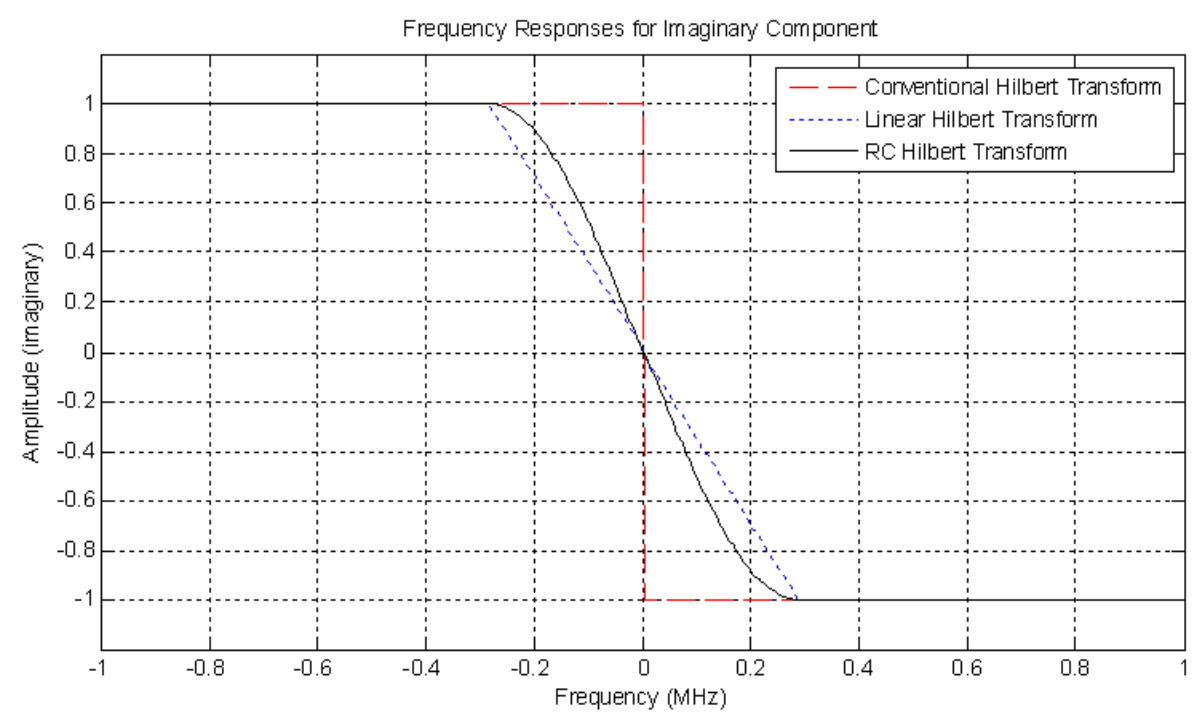

그림 7. 기존 및 제안된 힐버트 변환의 주파수 응답 특성

Fig. 7. Frequency Responses of conventional and proposed Hilbert Transforms 
이러한 힐버트 변환을 적용하면 그림 8과 같은 변환이 가능하고 기존 힐버트 변환을 적용했을 때보다 $\mathrm{Q}$ 채널 데 이터의 오류를 적게 할 수 있다.

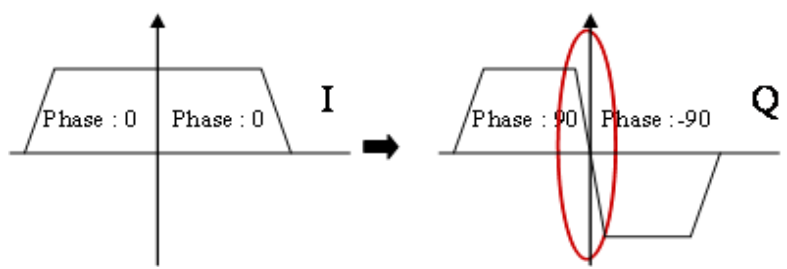

그림 8. 제안된 힐버트 변환을 이용한 । 신호로부터의 $Q$ 데이터 변환

Fig. 8. $Q$ data transform from I data by using proposed Hilbert Transform

또한 제안된 힐버트 변환을 사용함으로써 더욱 정확한 SNR(Signal to Noise Ratio) 및 EVM(Error Vector Magnitude)을 계산할 수 있다. 다음은 SNR 및 $\mathrm{EVM}$ 의 계산식이 다 $^{[15]}$.

$$
\begin{gathered}
S N R=20 \log \left[\frac{\sqrt{\frac{1}{N} \sum_{j=1}^{N} I_{j}^{2}}}{\sqrt{\frac{1}{N} \sum_{j=1}^{N} \delta I_{j}^{2}}}\right](d B), \\
E V M=\left[\frac{\sqrt{\frac{1}{N} \sum_{j=1}^{N}\left(\delta I_{j}^{2}+\delta Q_{j}^{2}\right)}}{\sqrt{I_{\max }^{2}}}\right] \times 100(\%),
\end{gathered}
$$

여기서 $\mathrm{N}$ 은 측정대상 샘플 수, $\delta I$ 및 $\delta Q$ 는 $\mathrm{I}$ 및 $\mathrm{Q}$ 축 방향 의 에러값, $I_{\max }$ 는 파일럿이 제거된 상태에서 I 축 방향으 로의 가장 큰 값이다.

\section{3. $\mathrm{CIR}$ 측정}

제안된 시스템에서 DTV 방송 채널 환경을 분석하기 위 해서 측정된 I 채널 데이터의 필드 동기 신호를 추출하여 $\mathrm{ATSC}$ 표준의 필드 동기용 PN 시퀀스와의 상호상관(correlation)에 의해 측정된 CIR I 채널 데이터를 다음과 같이 적용한다. 측정된 CIR I 채널 데이터는 데이터 분석에서와
같이 측정된 CIR I 채널 데이터에 힐버트 변환을 적용하여 $\mathrm{Q}$ 채널 데이터를 산출한다. 이렇게 계산된 $\mathrm{I}$ 와 $\mathrm{Q}$ 채널 데이 터를 이용하여 보다 정확한 다중경로 신호의 크기를 측정 한다. CIR 측정을 위한 I 채널 데이터는 ATSC DTV의 필 드 동기신호로부터 검출되므로 수신조건이 매우 열악한 상 황이라도 필드 동기만 검출할 수 있으면 CIR 정보의 추출 또한 가능하므로 비디오 신호의 수신이 불가능한 SNR $15 \mathrm{~dB}$ 이하의 열악한 수신환경에서도 적용될 수 있다.

그림 9에서는 $\mathrm{CIR}$ 을 측정하는 과정을 보여준다. CIR I 채널 데이터 측정과정은 하드웨어에서 구현되어 측정 및 평균과정을 실시간으로 수행한다.

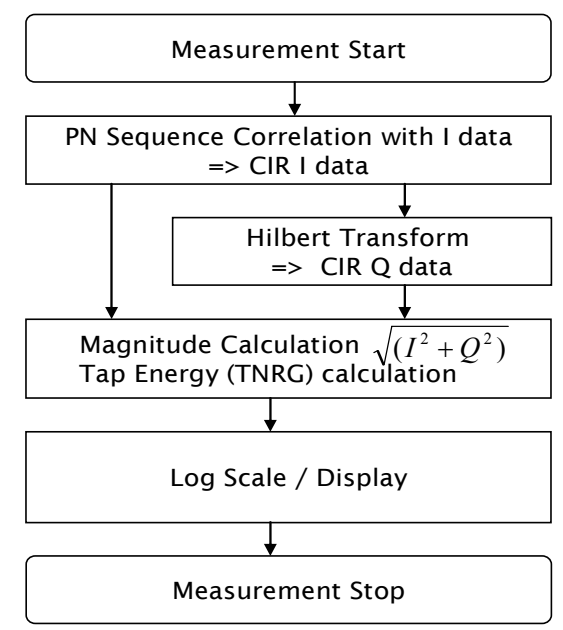

그림 9. CIR 측정 프로세스

Fig. 9. CIR measurement process

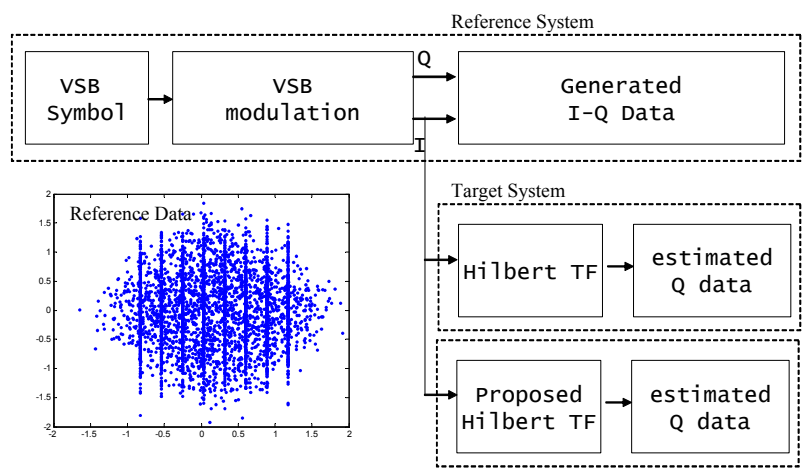

그림 10. $Q$ 채널 데이터 변환 모의실험 시스템

Fig. 10. Simulation system for $Q$ channel data transform 


\section{IV. 모의실험결과}

\section{1. 데이터 변환}

\section{1 이상적인 VSB 데이터 변환 실험}

제안된 채널분석시스템의 데이터 변환 성능을 검증하기 위해 그림 10 과 같은 모의실험 시스템을 구축하였다. 이상 적인 $21.52 \mathrm{MHz}$ 의 I, Q 기준 데이터(Reference data) 각각 4096 샘플에 대해서 $21.52 \mathrm{MHz}$ 의 I 채널 데이터만을 이용 하여 기존의 힐버트 변환과 제안하는 개선된 힐버트 변환 을 적용하여 그 결과를 기준 데이터와 비교하였다. 기준 데이 터는 120 탭의 $\mathrm{RC}$ 필터를 적용하여 생성되었으며 $\mathrm{AWGN}$ (Additive White Gaussian Noise) 등 기타 노이즈는 고려하 지 않은 이상적인 데이터이다.

그림 11은 I 채널 데이터로부터 Q 채널 데이터를 추출한 결과를 방식별로 비교한 것이다. 4,096개의 샘플에 대해서 전체 샘플에 대한 에러의 총합을 기준으로 성능을 비교하 면 기존 힐버트 변환을 사용한 방식이 $-22.2 \mathrm{~dB}$ 이며 제안한 방식 중 선형 힐버트 변환은 $-36.2 \mathrm{~dB}, \mathrm{RC}$ 힐버트 변환은 $-48.6 \mathrm{~dB}$ 로 각각 약 $14.0 \mathrm{~dB}, 26.4 \mathrm{~dB}$ 가량의 성능개선이 있음 을 알 수 있었다.

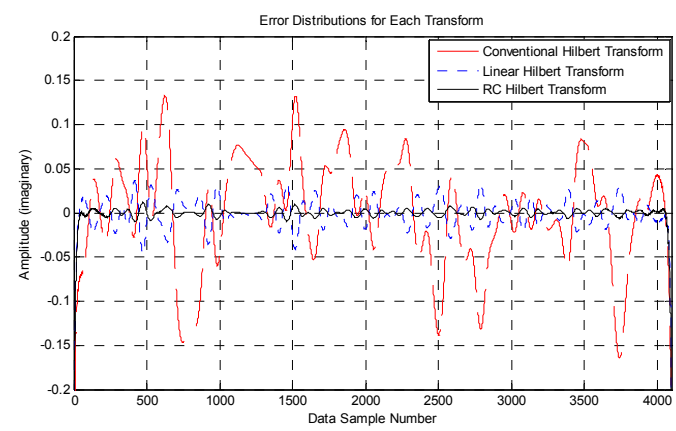

그림 11. $Q$ 채널 데이터 에러 비교

Fig. 11. Comparison of $Q$ channel data errors

그림 12 에서는 원래의 데이터에 대한 힐버트 변환된 데이 터의 성상도(constellation)를 비교하였다. 기존 힐버트 방식 은 원래 데이터로부터 많이 벗어나지만, RC 힐버트 변환을 사용하면 원래의 데이터 값과 거의 같음을 알 수 있다.

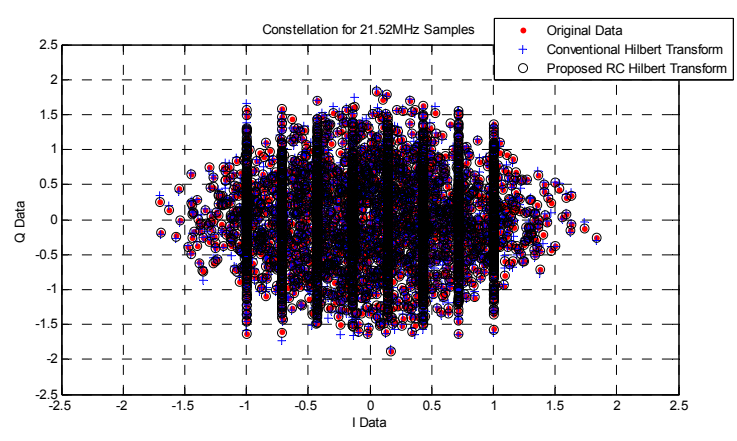

그림 12. 원래 데이터와 힐버트 변환된 데이터의 성상도

Fig. 12. Constellations of original data and Hilbert Transformed data

\section{2 실측데이터 변환 실험}

제안된 채널분석시스템의 데이터 변환 성능을 실제 측정 데이터를 이용하여 검증하기 위해 그림 13 과 같은 모의실 험 시스템을 구축하였다. VSB 변조기로 만들어낸 VSB RF 신호를 Agilent사의 $89441 \mathrm{~V}$ 벡터신호분석기를 이용하여 측정하고 $21.52 \mathrm{MHz}$ 의 I, Q 기준 데이터 4,096 샘플을 저장 하였다. 측정된 I 채널 데이터로부터 기존의 힐버트 변환과 제안하는 힐버트 변환들을 각각 적용하여 기준 데이터와 그 결과를 비교하였다.

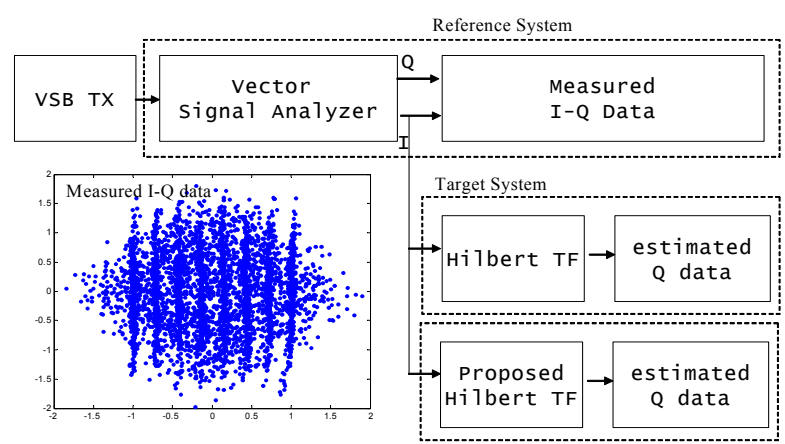

그림 13. $Q$ 채널 데이터 변환 실험실 측정 시스템

Fig. 13. Laboratory test system for $Q$ channel data transform

그림 14 와 그림 15 에서 전체 샘플에 대한 에러의 총합을 기준으로 성능을 비교하면 기존 힐버트 변환을 사용한 방 식이 $-21.6 \mathrm{~dB}$ 이며 제안한 방식 중 선형 힐버트 변환은 $-34.0 \mathrm{~dB}, \mathrm{RC}$ 힐버트 변환은 $-40.0 \mathrm{~dB}$ 로 각각 약 $12.4 \mathrm{~dB}$, $18.4 \mathrm{~dB}$ 의 성능개선이 있음을 알 수 있었다. 앞서 이상적인 기준 데이터에 대한 실험에서 보다는 에러 총합이 더 크긴 
하였으나 기존 변환 방식보다 제안된 변환 방식을 사용함 으로써 성능향상이 있음을 알 수 있다.

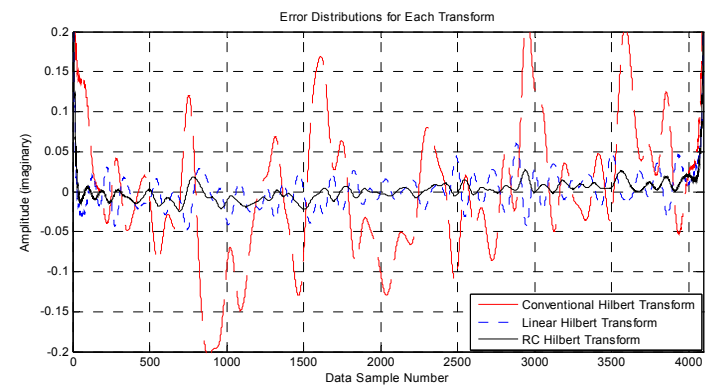

그림 14. 실측데이터에 대한 $Q$ 채널 데이터 에러

Fig. 14. $Q$ channel data errors on measured data

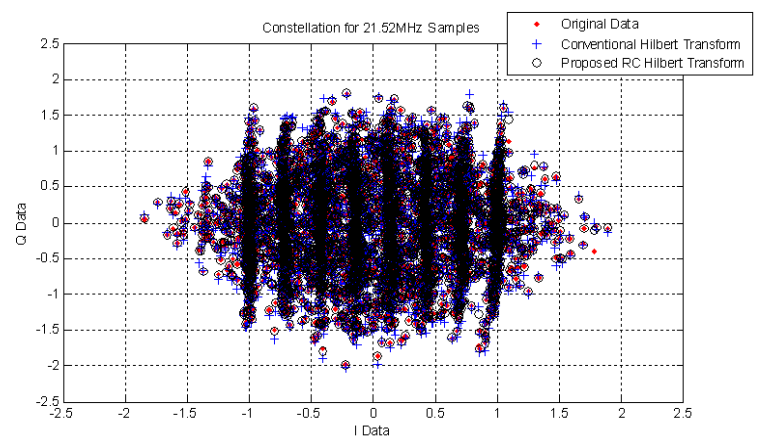

그림 15. 각 방식의 성상도 비교

Fig. 15. Comparison of constellations by each transform

\section{CIR 변환}

제안된 채널분석시스템의 $\mathrm{CIR}$ 측정 성능을 비교하기 위 해 그림 16 과 같은 실험 시스템을 구축하였다. 채널은 표 1 과 같은 브라질 $\mathrm{E}$ 채널을 사용하였다. 채널 발생 장치로는

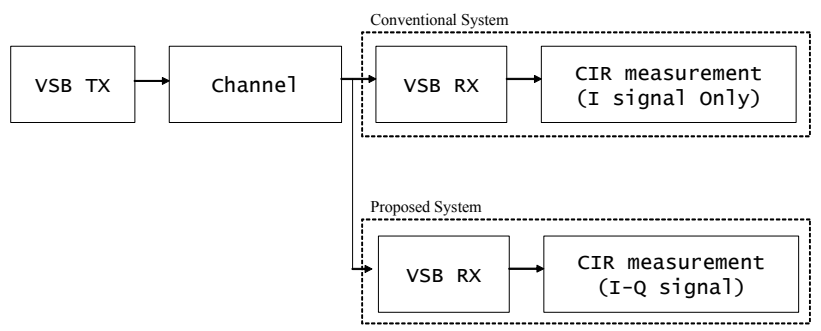

그림 16. CIR 측정 시스템 비교

Fig. 16. Comparison of CIR measurement systems
$\mathrm{R} \& \mathrm{~S}$ 사의 테스트 송신기인 $\mathrm{SFQ}$ 가 사용되었다.

표 1. 브라질 $\mathrm{E}$ 채널 파라미터

Table 1. Brazil E Channel Parameters

\begin{tabular}{|c|c|c|c|c|}
\hline Ensemble & Parameter & Path 1 & Path 2 & Path 3 \\
\hline \multirow{2}{*}{ Brazil E } & Delay $(\mu \mathrm{sec})$ & 0 & 1 & 2 \\
\cline { 2 - 5 } & Attenuation $(\mathrm{dB})$ & 0 & 0 & 0 \\
\hline
\end{tabular}

그림 17 과 그림 18 은 기존 $\mathrm{CIR}$ 측정방식으로 측정한 CIR I 채널 데이터와 제안한 알고리즘에 의해 복소 데이터 로 변환하고서 측정한 결과를 비교한 것이다. 이 두 그림을 비교해 보면 I 채널 데이터만으로 측정한 경우 위상 차이에

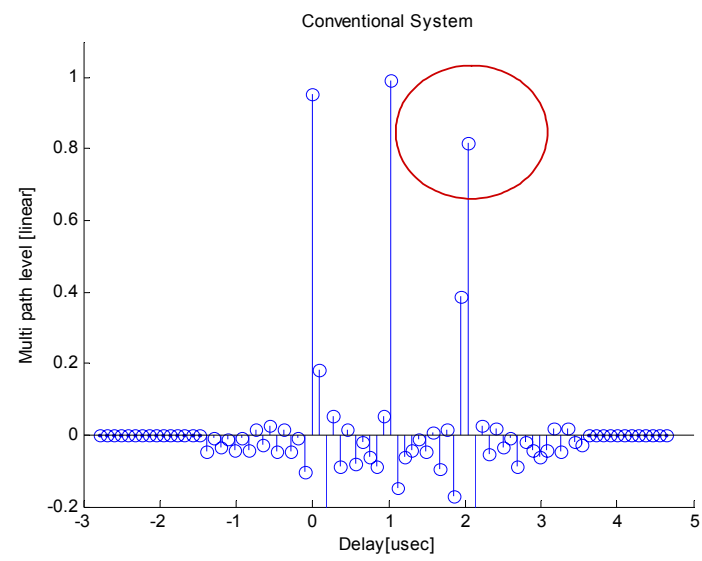

그림 17. CIR I 채널 측정데이터

Fig. 17. CIR I channel measured data

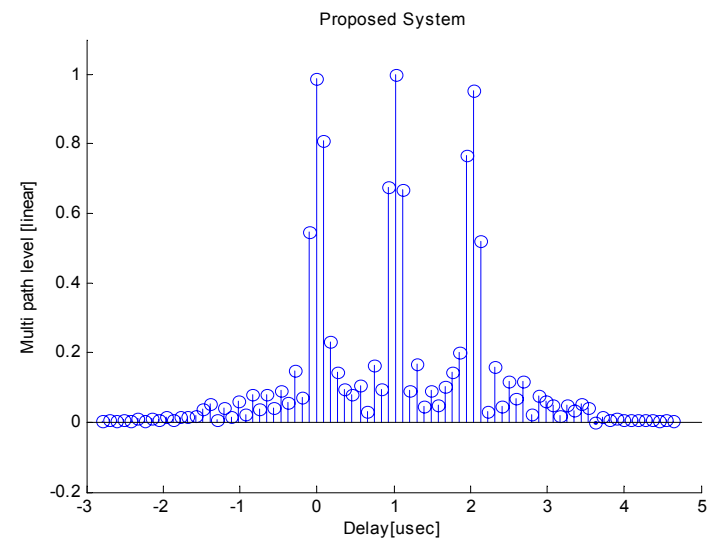

그림 18. 제안한 $\mathrm{CIR}$ 측정 결과

Fig. 18. Proposed CIR measurement result 
의해서 각각의 고스트 성분이 균일하지 않으나 위상보완을 통한 I-Q 채널 데이터를 이용함으로써 그 오차가 많이 개선 됨을 알 수 있다. 그림에서는 선형 스케일을 사용하였으나 로그 스케일 $(\log \mathrm{scale})$ 을 사용한다면 미약한 고스트 신호 도 검출할 수 있다.

\section{V. 구현 및 적용}

1. 하드웨어 개요

하드웨어 구현을 위하여 5 세대 수신기 칩세트를 이용하 여 I 데이터를 추출하였으며 제안한 RC 힐버트 변환 알고 리즘을 적용하였다. 하드웨어는 그림 19 와 같이 실시간 데 이터를 저장하고 USB 케이블로 연결된 통합측정분석시스 템 $\left(\mathrm{IMAS}^{[16][17]}\right)$ 을 통해서 $\mathrm{Q}$ 채널 데이터 복원 및 채널정보 분석 등을 수행한다.

그림 20과 같이 복조 된 데이터로부터 SNR, EVM 등을 측정할 수 있으며 채널정보에서는 주요 고스트 정보, 상대 지연시간, 탭 에너지 등을 계산한다.

\section{2. 필드시험결과}

개발된 장비의 채널 및 데이터 분석 성능을 검증하기 위 해 채널분석 측정 장비를 여수지역의 DOCR 및 분산중계 망 필드테스트에 각각 적용하였다. DOCR 측정은 2008년
11월 11 일부터 4 일에 걸쳐 수행하였으며 중계소에서의 $\mathrm{DOCR}$ 의 피드백 신호에 대한 성능 측정 및 필드 채널 정보 등을 수집하였다. 측정된 데이터는 힐버트 변환에 의한 절 대 크기 측정 및 로그 스케일로 고스트별 상대 크기를 측정 하고 비교하였다. 피드백신호 성능측정 방법은 DOCR의 출 력을 높여 임계점에 다다랐을 때 DOCR 입력단의 모니터 출력을 채널분석기에 연결하여 측정하였다. 이로부터 현재 DOCR로 입력되고 있는 고스트 신호의 크기를 측정하여 피 드백 신호 성능을 측정할 수 있다. 분산중계망 측정은 2009 년 2월 중순에 일주일에 걸쳐 수행하였으며 여수, 구봉, 쌍 봉, 문수, 호명 등 5 개 중계소에 설치된 분산중계기의 신호 에 대해서 다중경로신호를 분석하였다. 필드테스트의 결과 그림 21 과 같이 일반 세트톱박스에서는 수신이 어려운 $\mathrm{SNR} 6.2 \mathrm{~dB}$ 지역에서도 고스트 분포의 측정이 가능하였으 며 수신기에 따른 다중 경로 간섭에 의한 수신 불량 현상을 설명할 수 있었다.

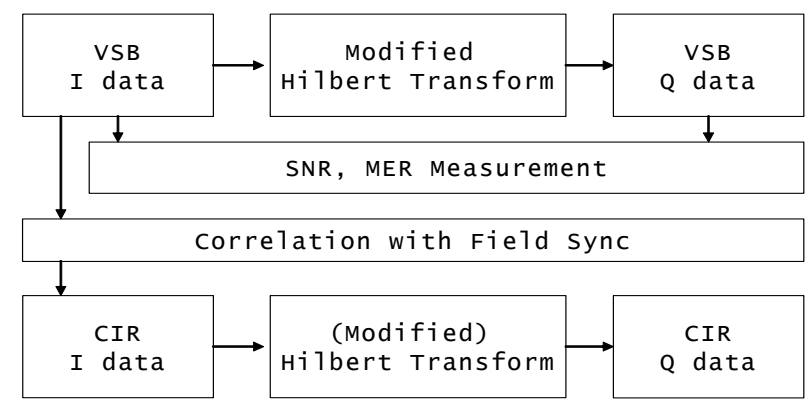

그림 20. CIR 분석시스템 신호분석부 구성

Fig. 20. Measurement structure of CIR analysis system

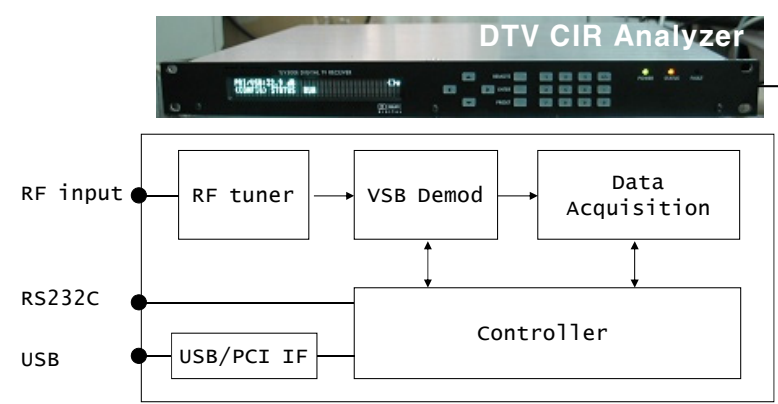

USB2.0

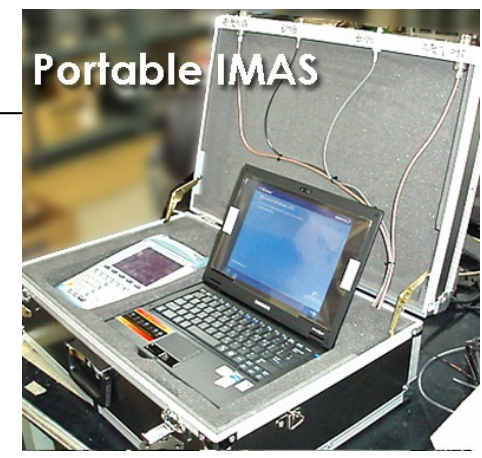

그림 19. 채널분석 하드웨어 시스템 구성

Fig. 19. Block diagram of $\mathrm{CIR}$ analysis hardware 


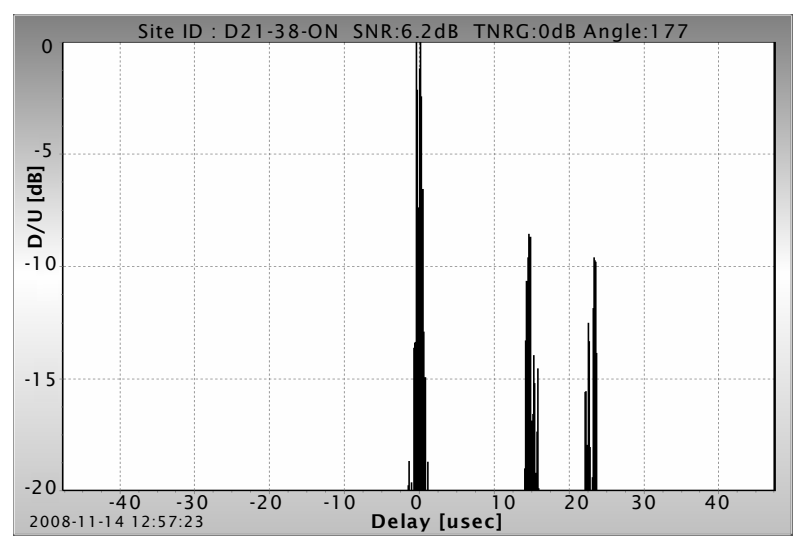

그림 21. 여수 지역 채널 측정결과 샘플

Fig. 21. Sample of CIR test results in Yeosu area

\section{V. 결 론}

본 논문에서는 ATSC DTV 방송수신환경을 분석하기 위 한 DTV 방송 채널분석 시스템의 기술적 요구 사항을 제시 하고 상용 DTV 수신 칩세트 솔루션을 이용하여 효율적으 로 이를 구현하는 방법을 제시하였다. 상용 DTV 수신 칩에 서 얻을 수 있는 기저대역의 I 채널 데이터로부터 제안된 선형 및 $\mathrm{RC}$ 힐버트 변환 방법을 통해서 $\mathrm{Q}$ 채널 데이터를 획득하여 $\mathrm{VSB}$ 수신신호의 위상정보를 보다 정확하게 추출 해 낼 수 있다. 이를 통해 수신신호의 SNR, EVM, 성상도 등을 추출할 수 있으며 채널 임펄스 응답의 복소 분석을 통해서 기존 데이터에서의 원점 부근 위상정보 손실에 의 한 위상 오차를 극복하였다.

제안된 시스템은 하드웨어로 구현되어 동일채널중계기 및 분산중계망 필드테스트에 시범적으로 적용되었다. 특히 동일채널중계기의 피드백 신호에 대한 성능측정에도 활용 되었으며 다중경로간섭환경의 분석을 통한 세대별 수신기 의 성능분석에도 적용되었다. 실험에서는 $\mathrm{SNR}$ 이 $6.2 \mathrm{~dB}$ 정 도로 수신환경이 불량한 상황에서도 다중경로신호를 분석 함으로써 다중경로 간섭으로 말미암은 수신기의 수신 성능 불량 원인을 분석하는 등 채널환경 분석결과를 얻을 수 있 었다. 개발된 제품은 추가적인 연구를 통해 수신 단의 신호
품질을 향상하고 비디오 신호 분석 파라미터를 추가하여 채널분석과 비디오 분석이 가능한 측정차량용 기준 수신기 로 활용할 예정이다.

\section{참 고 문 헌}

[1] "ATSC Digital Television Standard, Rev. E with Amendments No.1 and 2", ATSC Standard A/53E, Dec. 2005.

[2] "Guide to the use of the ATSC Digital Television Standard, Rev. A", ATSC Recommended Practice A/54, Dec. 2003.

[3] 서영우, 유호진, 박민호, 박준성, 김규영, 서종수, "디지털 TV 실내수신 환경 분석”, 방송공학회 논문지, 제 13 권 제 5 호, Oct. 2008.

[4] "Receiver Performance Guidelines", ATSC Recommended Practice A/74, June 2004.

[5] ATSC, "Recommended Practice A/111: Design of Synchronized Multiple Transmitter Networks," Sep. 2004.

[6] K. Salehian, Y. Wu, and B. Caron, "Design Procedures and Field Test Results of a Distributed-Translator Network, and a Case Study for an Application of Distributed-Transmission," IEEE Trans. Broadcasting, vol. 52, no. 3, pp. 281-289, Sep. 2006.

[7] 왕수현, 서영우, 목하균, 이재영, 이용훈, 김흥묵, "DTV 분산중계망 필 드테스트 결과," 방송공학회 논문지, Vol. 13, No. 4, pp. 463-478, Sep. 2008.

[8] Y.W. Suh, et al, "Field Test Results of Digital On-Channel Repeaters in the DTV Transmission Network in Korea", 56th IEEE Broadcast Symposium, Oct. 2006.

[9] Y.W. Suh, et al, "Comparison of Distributed Translators", 57th IEEE Broadcast Symposium 2007, Oct. 2007.

[10] http://www2.rohde-schwarz.com/product/EFA50/53.html.

[11] S.I. Park, J. Lee, H. M. Kim, W. Oh, "Transmitter Identification Signal Analyzer for Single Frequency Network", IEEE Transactions on Broadcasting, pp. 383-393, Vol. 54, Issue 3, Part 1, Sep. 2008.

[12] S.C. Yim, C.C. Su, M.T. Shiue, L.Y. Huang, C.K. Wang, S.J. Jou, W.I. Way, "A New VSB Modulation Technique and Shaping Filter Design", IEEE International Symposium on Circuit and Systems, pp. 312-315, Vol. 4, May 1996.

[13] http://www.wikipedia.org, "Hilbert Transform", 2009.

[14] H.N. Kim, Y.T. Lee, S.W. Kim, "Mathematical Modeling of VSB-Based Digital Television Systems", ETRI Journal, Vol. 25, Num. 1, Feb. 2003.

[15] L. Gumm, "Signal to Noise Relationships In 8-VSB", http://www. tek.com/Measurement/App_Notes/Technical_Briefs/25W_13224_0.pdf.

[16] 김영민, 서영우, 목하균, 권태훈, 이상길, "DTV 필드테스트를 위한 통 합 측정 및 분석 시스템 개발", 방송공학회 논문지, 제 10 권 제 4 호, pp.599-609, Dec. 2005.

[17] Y.W. Suh and S.H. Kim, et al., "A Novel Integrated Measurement System for Digital Broadcasting," Proceeding of IEEE ICCE 2009, Jan. 2009. 


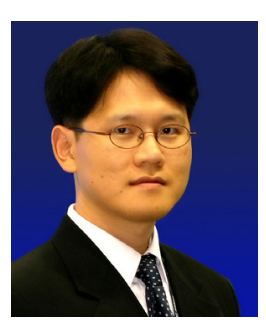

\section{서 영 우}

- 1991년 3월 1995년 2월 : 서울대학교 제어계측공학과 (공학사)

- 1995년 3월 1997년 2월 : 서울대학교 제어계측공학과 (공학석사)

- 2007년 3월 현재 : 연세대학교 전기전자공학과 박사과정

- 1997년 3월 현재 : KBS 방송기술연구소 선임연구원

- 주관심분야 : 디지털 신호처리, RF 신호처리, DTV 전송시스템

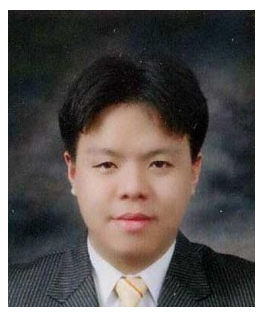

\section{이 재 권}

- 2002년 3월 2006년 2월 : 충남대학교 전자전파정보통신공학과 (공학사)

- 2006년 3월 2008년 2월 : 과학기술연합대학원대학교 이동통신 및 디지털방송공학과 (공학석사)

- 2006년 3월 2008년 3월 : 한국전자통신연구원 인지접속연구팀 석사과정연구생

- 2008년 3월 현재 : KBS 방송기술연구소 연구원

- 주관심분야 : VSB 및 OFDM 전송시스템, 디지털 RF, 무선인지기술

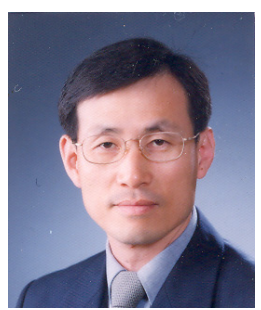

\section{목 하 균}

- 1976년 3월 1980년 2월 : 서울대학교 전기공학과 (공학사)

- 1980년 3월 1982년 2월 : 한국과학기술원 전기및전자공학과 (공학석사)

- 1992년 9월 1995년 6월 : 무궁화위성(Koreasat) 탑재체(payload) 현장 훈련 파견연수(영국, 미국)

- 1991년 3월 2000년 2월 : 한국과학기술원 전기및전자공학과 (공학박사)

- 1982년 8월 현재 : 한국방송 방송기술연구소 수석연구원

- 주관심분야 : 지상파 디지털TV 방송시스템, RF 및 위성 시스템, 위성방송

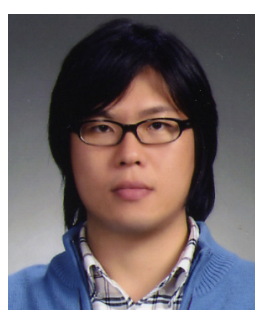

\section{최 진 용}

- 1999년 3월 2004년 2월 : 연세대학교 전기전자공학과 (공학사)

- 2004년 3월 2006년 2월 : 연세대학교 전기전자공학과 (공학석사)

- 2006년 8월 현재 : 연세대학교 전기전자공학과 박사과정

- 주관심분야 : 디지털 신호처리, 디지털 방송통신시스템, 중계시스템

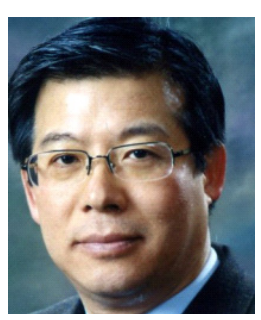

\section{서 종 수}

- 1975년 : 연세대학교 전자공학과 (공학사)

- 1983년 : Univ. of Ottawa, Canada 전기공학과 (공학석사)

- 1998년 : Univ. of Ottawa, Canada 전기공학과 (공학박사)

- 1975년 1981년 : LG정밀 중앙연구소

- 1987년 1989년 : IDC, Canada 책임연구원

- 1990년 1992년 : 삼성종합기술원 정보 시스템 연구소 수석연구원

- 1992년 1995년 : CAL, Canada 책임 연구원

- 1995년 현재 : 연세대학교 전기전자공학과 정교수

- 주관심분야 : 디지털 통신 / 방송 시스템, Resource allocation, CDMA, OFDM 